\title{
Electronic system for documentation of the grape gene pool for assessing the ecological potential of varieties and their use in breeding*
}

\author{
Irina Ilina $^{1 * *}$, Valeriy Petrov ${ }^{1}$, Daria Popova $^{2}$, Viktoriya Sokolova $^{1}$, Irina Machneva ${ }^{1}$ \\ ${ }^{l}$ Federal State Budget Scientific Institution «North Caucasian Federal Scientific Center of \\ Horticulture, Viticulture, Wine-making», str. 40 Let Pobedy, 39, Krasnodar, 350901, Russia \\ ${ }^{2}$ «Small Innovative Enterprise «AmpeloInformProduct» LLC, st. Vostochno-Kruglikovskaya, house \\ 69, office 24 6350901, Krasnodar, 350901, Russia
}

\begin{abstract}
The need to create a multifunctional electronic system for documentation of the grape gene pool, focused on the characteristics of its ecological potential, has been updated. The step-by-step development of the system architecture of the grape gene pool documentation program, including the program interface, is presented. As the characteristics that most fully describe the economically valuable characteristics of grape varieties, 85 indicators were selected, and they were grouped according to functional characteristics into 9 groups. The logical structure was created and the physical design of the database was carried out. An electronic information Database has been formed, the development of which is focused on the characteristics of the obtained potential of genotypes carrying breeding significant traits, their classification, certification and areas of use. In the process of research, the screening of the grape gene pool by environmental parameters was carried out, which are based on analytical methods grouped that make it possible to obtain a complex of physiological and biochemical indicators characterizing the resistance of plants to extreme stress factors of the environment. To implement the task of varieties selection according to specified criterions, three algorithms are implemented depending on the type and user requirements for the selected varieties. In view of the environment stress full increasing and the need to focus on the ecological characteristics of varieties, the algorithms for their assessment have been developed with a focus on weather and climatic peculiarity. In order to rank variety forms according to the degree of resistance to dehydration and extreme low and high temperatures, a scale of tester varieties (standards) from low to highly resistant has been developed. The original own scale is proposed to assess every type of resistance.
\end{abstract}

Under the contemporary conditions of climate change, the grape plants are exposed to a complex of stressful environmental factors. Analysis of long-term data on changes in climatic

\footnotetext{
${ }^{*}$ The research was carried out with the financial support of the Kuban science Foundation in the framework of the scientific project № МФИ-20.1/19

${ }^{* *}$ Corresponding author: iailyna64@gmail.com
} 
factors indicates significant changes occurring that have a negative impact the stability, productivity and cultivation term of vine plantations, and the quality of products. In achieving stability and controllability of grape production, the formation and improvement of regional grape assortments in terms of adaptability, productivity and quality of varieties are very important [1]. The issues of increasing in the resistance of grape plants under the conditions of abiotic and biotic stressors manifestation occupy one of the main places in solving the problem of constructing the highly productive ampelocenoses [2]. In this regard, the relevance of research is due to the urgent need for varieties with high complex ecological stability [3]. The solution of these problems is possible with the use of information technologies that allow us to accumulate large amounts of data, carry out the system analysis, develope the mathematical models for optimizing the assortment for specific soil and climatic conditions, as well as for carrying out traditional and clonal grape breeding based on target characteristics $[4,5,6,7]$.

Many countries of the world are implementing the national programs for the preservation and use of plant genetic resources (France, USA, India, Italy, Spain, Portugal, Germany, etc.), in which the most important direction is given to the identification and breeding use of donors of the most important grape breeding traits $[8,9]$. Currently, the collection and storage of the grape variety information is implemented in national databases: Italian Vitis Database (VitisDB) - a publicly open Italian database Vitis L., describing more than 2300 samples according to 9 characteristics; La Vigne et le vin - French database containing information on 577 varieties by 8 parameters; Portuguese Vitis Database - Portuguese Vitis L. database describing about 300 varieties by 10 parameters; Greek Vitisdatabase - Greek Vitis L. database with ampelographic description of 270 varieties by 10 parameters; Swiss Vitis Microsatellite Database (SVMD) - Swiss microsatellite sequence database of 170 grape varieties; Vitis International Variety Catalogue is an international grape catalog containing information of more than 1500 varieties [10]. Of all the databases, the latter describes the varieties most fully, the characteristics are divided into functional groups: species, generic origin, data on breeding and genetics, passport data, microsatellite data, information on the distribution of varieties in the countries growing this crop.

Thus, the main purpose of the development was the screening and creation of a multifunctional electronic system for documentation of the grape gene pool, focused on the characteristics of its ecological potential.

The place and conditions for the research are the moderately continental unstable climate of the South of Russia, industrial plantings of grapes, ampelocollection in the AZESVaW NCFSCHVW (Anapa). The Anapa ampelographic collection is the largest depository of the gene pool of grape varieties in Russia, imported from various countries of Europe, Asia, America and regions of Russia. It contains 4921 variety saplings, including Vitis vinifera $L$. - 2975, V. amurensis Rupr. - 40, V. labrusca L. -50 , interspecific varieties $V$. vinifera $L$. x $V$. amurensis Rupr. $-210, V$. vinifera $L$. x V. labrusca L. -168 , complex interspecific hybrids $V$. vinifera $L$. $\mathrm{x}$ hybrids $\mathrm{SV}-220, V$. vinifera $L . \mathrm{x} V$. amurensis Rupr. $\mathrm{x}$ hybrids $\mathrm{SV}-70$ and other samples.

The peculiarity of methodological approaches to the study of the gene pool is associated with the fact that the objects of research are perennial plants, the annual development cycle of which is closely related to extreme biotic and abiotic environmental factors, as well as to the genetic and biological characteristics of the origin of most species through interspecific and intraspecific hybridization. Large paratypical variability within a variety (clone) and even within one plant makes it difficult to objectively describe the characteristics of both morphological (size, shape, color) and biological (passage, developmental phases, resistance to environmental stress factors, level of realization of the economic productivity potential). All this factors require an integrated approach with the simultaneous use of mathematical and statistical methods of analysis. 
At the first stage of work, when creating a software product, the following were developed: the system architecture and the interface of the grape gene pool documentation program, the basis of which is a database - a program that allows you to receive and store large volumes of information related.

To determine the main characteristics that most fully describe the economically valuable characteristics of grape varieties and are recommended for inclusion in the database, the requirements of various users to the system being developed were analyzed, as a result of which 85 indicators were selected, and grouped according to functional characteristics: general characteristic of the variety (14 characteristics); legal basis (it includes the information about authors, copyright holder, origin of the variety, date of including into the State Register; confirming the right to a breeding achievement - total 9 characteristics); resistance to bio- and abiotic factors - information on the resistance / susceptibility of the variety to various stress factors of the environment (diseases, vermins, temperature and water stress - 19 parameters); phenological indicators (7 characteristics); growth characteristics (6 characteristics); agrobiological characteristics of the crop - (7 characteristics); physical and chemical composition of grape berries (7 indicators); tasting assessments - for grape; raisins; grape juice, wine (13 characteristics); donorship - information about whether a variety can be a donor of resistance to biotic factors (16 characteristics) [11].

At the next stage, the logical design of the database was carried out, that is, the creation of its logical structure based on a specific model, for example, a relational data model (this is a model that describes how to organize data in tables and how to determine the relationships between them).

In order to control the integrity and reliability of the data, the physical design of the database was carried out, that is, the database management system was developed and its description was given.

To implement the task of varieties selecting according to the specified criterians, three variants of the algorithm have been implemented, depending on the type and users requirements for the selected varieties:

- selection of varieties for creating the new varieties (for breeders);

- selection of varieties for a variety conveyor (for agronomists; specialists; farmers cultivated grapes);

- selection of varieties for high-quality wine-making (for wine-makers and wineproducing specialists).

The algorithm developed for selecting the varieties according to the assighnment criterions is identical for all query options, but the selection criterions and characteristics of varieties received together with the selection result are different. Depending on the purpose of the selection of the variety, the characteristics and parameters that must be selected from the base will be different.

The purpose of new cultivar forms breeding is cultivar improvement, ensured the availability of a high-yielding assortment that is resistant to bio- and abiotic environmental factors. For this, it is necessary to select the future "parents", which will be gene donors.

Particularly important inherited traits when creating the new varieties are: high productivity and quality of grapes, resistance to phylloxera, resistance to low temperatures and slignt frost, water deficiency, seedlessness, early ripening, nutmeg aroma, large berry.

The input parameters for selection are: the direction of the variety use and the ability of the variety to be a donor of certain economically valuable traits. Obligatory parameters for selection can be only one or several inherited traits transmitted by donors when creating a new variety. The algorithm for selecting the varieties for creating variety forms is shown in Fig. 1.

It should be noted that the biological characteristics of grapes, which have a long-term development cycle, as well as two plant components (rootstock, scion), due to the need to 
graft a variety on the corresponding rootstock in order to solve a number of problems (resistance to phyloxera, to lime, etc.), introduce a certain specificity into the information system. etc.). In this case, the root stock can significantly change the physiology of a perennial plant, which must be taken into account when describing the forms and varieties cultivated. In addition, the grapes as the genus Vitis Vinifera show significant genetic polymorphism. The numerous interspecific hybrids, clones and mutant forms are found in the grape gene pool. In addition, ripening times organoleptic assessment, productivity, the presence of immunity genes, and so on are important for varieties. All this as a whole creates certain difficulties in the development of an information system that must take into account all the above features.

In this regard, it was necessary to select not only the features describing the characteristic features of the sample, but also, to determine their priority, and to unify them.

The most common abiotic stressors are dehydration, high temperatures in the second half of the growing season, and temperature drops to critical values in autumn, winter and spring. According to this, studies were carried out to establish biochemical parameters most fully characterized the resistance of grape varieties to the stresses of the winter and summer periods.

As the results of research for the period 2007-2019 in the Anapo-Taman zone of Russia, the most significant biochemical indicators of grape varieties adaptation to summer stressors are: the content of sucrose, starch, proline, protein, ascorbic acid, chlorophyll $a+b$, carotene, indoleacetic acid, abscisic acid, malonic dialdehyde in the leaves, the sum of phenolcarboxylic and organic acids $[12,13]$.

The assessment of winter damages to grape plants was directed to four components of winter hardiness: resistance to early frosts, frost resistance during dormancy, recovery from dormancy, and resistance to spring slight frosts. The biochemical indicators of interspecific grape hybrids adaptation to the stressors of the winter period include: the content of sucrose, starch, proline, protein, abscisic acid, malonic dialdehyde, the amount of phenol carboxylic acids, the amount of cations $[14,15]$.

In addition to optimizing the structure of the database related to its conceptual orientation, as well as the program for working with it, it was necessary to improve the algorithms for assessing the ecological potential of grape genetic resources.

We have developed an algorithm consisting of logical applied analytical methods that allow us to assess the degree of manifestation of protective-adaptive reactions in grape samples, creating a methodological basis for studying genotype-environmental interactions and allowing us to determine quickly the indicators of grape variety resistance to the most common abiotic stress factors.

The peculiarity of these algorithms is the orientation towards the weather and climatic specifics. Diagnostics of stability includes two-level: field and laboratory, which increase in the reliability of the results obtained. An increase in the accuracy of the results obtained is also promoted by the modeling of stress conditions, regime parameters of which were specially developed by us for grapes, taking into account its biological characteristics.

In order to determine the sample resistance degree to the above-mentioned limiting environmental factors, the analytical methods were selected with the highest accuracy, some of which were modified by us for mass analyzes use. The methods are selected in order the indicators obtained with their using complement and / or correct each other. For example, the transition from the ecological to the production block of algorithms realizes by the method evaluated the resistance of the pigments to stress. Such following turn of methods makes it possible to obtain a systemic characteristic of the object under study.

As a result of the research, significant differences were found in the correlation coefficients between the main indicators of degree of grape plants resistance to abiotic stresses. For example, the correlation coefficient does not exceed -0.3-0.4 between two 
indicators of the degree of plant drought resistance as water-retaining capacity and the total water content of the leaves under optimum conditions, while under drought conditions it increases up to -0.6-0.8 depending on the genotypic features of the sample. In this regard, we carried out the assessment of plant response to stresses under model experimental conditions, which makes it possible to exclude the influence of a number of undesirable artifacts. To carry out the experiments the corresponding modes, of temperature and humidity have been developed, taking into account the biological capabilities of the objects studied.

In addition to diagnosing the grape resistance degree to abiotic stress factors, a qualitative assessment of photosynthesis closely related to plant productivity is required. In this regard, studies are being carried out aimed at identifying the genotypes with high photosynthetic characteristics. This will allow us to increase in the efficiency of using the grape genetic resources in breeding and production.

A special algorithm has been developed, associated with the assessment of the qualitative photosynthetic indicators, indirectly characterized the productivity potential of plants, and it increases in the value of the database for solving the practical problems, especially in breeding. The assessment of the photosynthetic qualitative indicators is based on the same principles then that for stability algorithm. The link between two algorithms is determination of pigments resistance degree to dehydration and high temperature. In addition, the photosynthetic parameters are determined in the mature leaves, in time of maximum manifestation of drought and the highest temperature.

To assess each type of resistance according to the blocks of the algorithm, a scale of varieties-testers or standards was created, which makes it possible to rank the samples studied. The need for testers is also due to the comparative rather than absolute nature of plant resistance to stress. For the scale of testers, the zoned, widespread varieties were selected, so if the evaluated variety is better, then it can be potentially included to a new assortment.

It should be emphasized that in the database being developed, the results of the physiological and biochemical assessment are entered into the "Additional" descriptor list, and the results of field observations, including the assessment of the resistance (score) of samples to diseases and vermins - into the ecological descriptor. This methodological approach allows us not only differentiating an information about the sample, but also applying the results separately. 


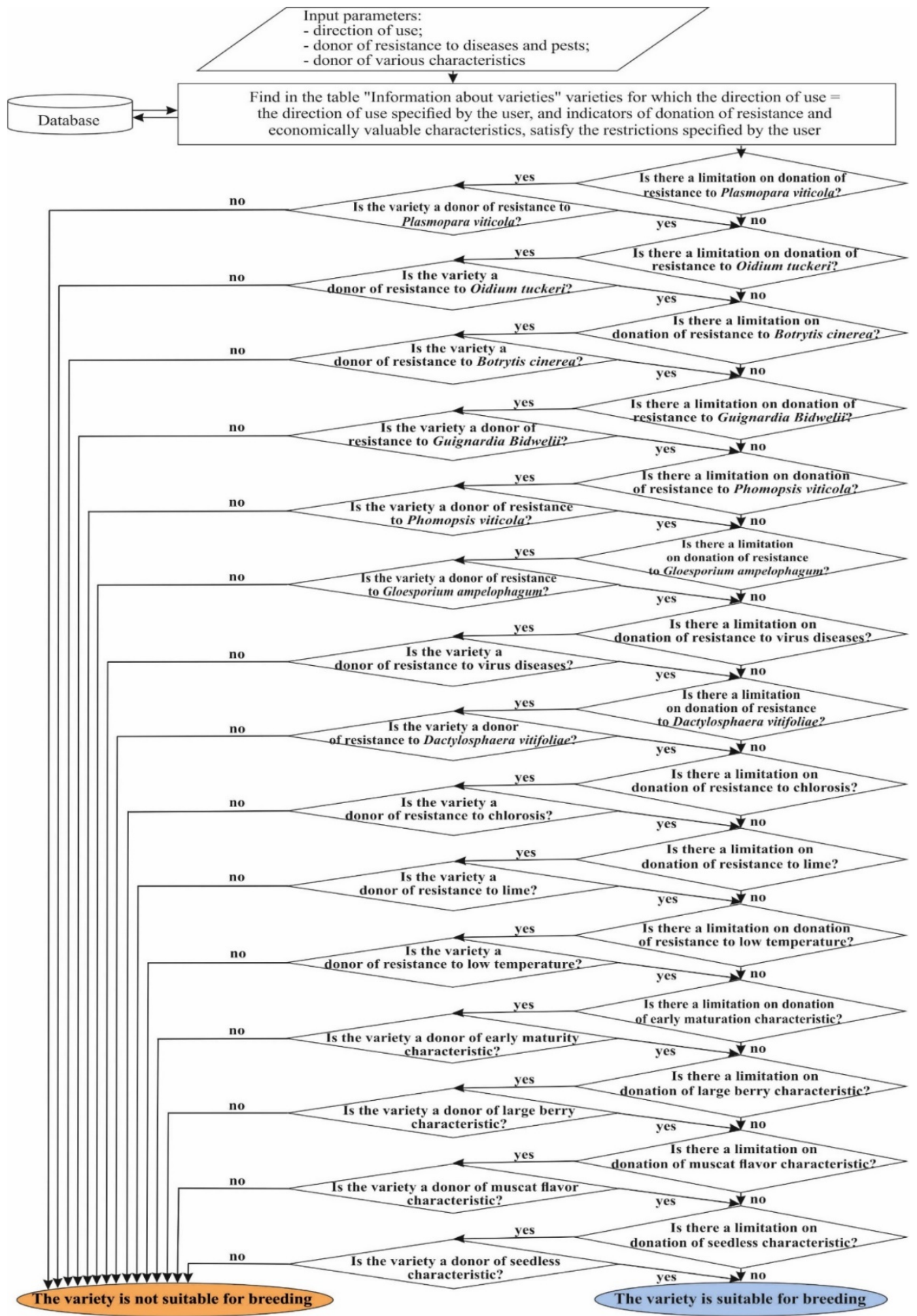

Fig. 1. Algorithm of grape varieties selection for breeding 
Thus, the developed electronic system of the grape gene pool documentation, is focused on the characteristics of variety ecological potential. The formed algorithms and related elements made it possible to create a conceptual model of a decision-making system for assessing the stress resistance of grape samples, and their use in different climatic zones, as for well as the selection of donors for breeding the new highly resistant to environmental stress factors genotypes. The features of the information system, determined by its conceptual orientation, make it possible to form the new methodological principles for the study, documentation and systematization of the grape gene pool. The use of algorithms creates prerequisites for a multisystematic analysis of protective and adaptive reactions, as well as processes associated with plant productivity, which increase in the amount of information and along with documentation of the gene pool, allow to conduct theoretical research in the field of studying the "genotype-environment interactions". The formed algorithm and accompanying elements made it possible to create a conceptual model of a decision-making system for a differentiated assessment of the stress resistance of grape samples and to use them in the different climatic zones.

\section{References}

1. E.A. Egorov, Herald of the Russian Academy of Sciences, 86(3), 242-247 (2016) https://www.elibrary.ru/download/elibrary_26068483_94483163.pdf

2. Sandro Sacchelli, Sara Fabbrizzi, Marco Bertocci, Enrico Marone, Silvio Menghini, Iacopo Bernetti, Journal of Cleaner Production, 166, 891-900 (2017) https://doi.org/10.1016/j.jclepro.2017.08.095

3. Kate Binzen Fuller, Julian M.Alston, Olena S.Sambucci, Wine Economics and Policy, 3(2), 90-107 (2014) https://doi.org/10.1016/j.wep.2014.09.001

4. Véronique Bellon-Maurel, Gregory M.Peters, Sonia Clermidy, Gustavo Frizarin, Carole Sinfort, Hernan Ojeda, Philippe Roux, Michael D.Short, Journal of Cleaner Production, 87, 119-129 (2014) https://doi.org/10.1016/j.jclepro.2014.09.095

5. Aunur Rofiq Muljarto, Jean-Michel Salmon, Brigitte Charnomordic, Patrice Buche, AnneTireau, PascalNeveu, Computers and Electronics in Agriculture, 140, 433-442 (2017) https://doi.org/10.1016/j.compag.2017.06.020

6. André Mendes Lemosa, Nelson Machadoab, Marcos Egea-Cortinesc, Ana Isabel Barros, Scientia Horticulturae, 262, 109096 https://doi.org/10.1016/j.scienta.2019.109096

7. Daniel Molitora, Helder Fragab, Jürgen Junk, Agricultural and Forest Meteorology, 291, 108024 (2020) https://doi.org/10.1016/j.agrformet.2020.108024

8. S.S. Ningthoujam, A.D. Talukdar, K.S. Potsangbam, M.D. Choudhury, Journal of Ethnopharmacology, 141 (1), 9-32 (2012) https://doi.org/10.1016/j.jep.2012.02.042

9. R.C.Agrawal, Sunil Archakb, R.K.Tyagi, Computers and Electronics in Agriculture, 84, 92-99 (2012) https://doi.org/10.1016/j.compag.2011.12.003

10. PaulaMoreno-Sanz, María Dolores, LoureiroBelénSuárez Scientia Horticulturae, 129, 433-440 (2011) https://doi.org/10.1016/j.scienta.2011.04.013

11. D.V. Popova, I.A. Ilina, V.S. Petrov, V.V. Sokolova Fruit growing and viticulture of South Russia, 6, 124-135 (2019) https://doi.org/10.30679/2219-5335-2019-6-60-124135

12. N.I. Nenko, I.A. Ilina, V.S. Petrov, M.A. Sundyreva, V.V. Sokolova, N.M. Zaporozhets, G.K. Kiseleva, T.V. Skhalyaho, Vestnik of the Russian agricultural science, 5, 40-45 (2019) https://doi.org/10.30850/vrsn/2019/5/40-45

13. Nenko N.I., Ilina I.A., Petrov V.C. [et al], Research journal of pharmaceutical, biological and chemical sciences, 10(1), 1903-1910 (2019)

http://www.rjpbcs.com/pdf/2019 10(1)/[250].pdf 
14. N.I. Nenko, I.A. Ilina, G.K. Kiseleva, E.K. Yablonskay, Academia Journal of Food Research, 7(1), 1-11 (2019) DOI: 10.15413/ajfr.2018.0105.

https://www.academiapublishing.org/journals/ajfr/abstract/2019/Jan/Nenko\%20et\%20al htm

15. N.I. Nenko, I.A. Ilina, G.K. Kiseleva, E.K. Yablonskay, Proceedings of the Latvian Academy of Sciences, 73(1), 56-65 (2019) https://doi.org/10.2478/prolas-2018-0046 